Regular Article

ISSN 1226-8267

Journal of Forest Science

Vol. 28, No. 4, pp. 205-211, Novembert, 2012

http://dx.doi.org/10.7747/JFS.2012.28.4.205

\title{
Variable Density Yield Model for Irrigated Plantations of Dalbergia sissoo Grown Under Hot Arid Conditions in India
}

\author{
Vindhya Prasad Tewari \\ Wood Energy Division, Institute of Wood Science and Technology, Bangalore 560003, India
}

\begin{abstract}
Yield tables are a frequently used data base for regional timber resource forecasting. A normal yield table is based on two independent variables, age and site (species constant), and applies to fully stocked (or normal) stands while empirical yield tables are based on average rather than fully stocked stands. Normal and empirical yield tables essentially have many limitations. The limitations of normal and empirical yield tables led to the development of variable density yield tables. Mathematical models for estimating timber yields are usually developed by fitting a suitable equation to observed data. The model is then used to predict yields for conditions resembling those of the original data set. It may be accurate for the specific conditions, but of unproven accuracy or even entirely useless in other circumstances. Thus, these models tend to be specific rather than general and require validation before applying to other areas. Dalbergia sissoo forms a major portion of irrigated plantations in the hot desert of India and is an important timber tree species where stem wood is primarily used as timber. Variable density yield model is not available for this species which is very crucial in long-term planning for managing the plantations on a sustained basis. Thus, the objective of this study was to develop variable density yield model based on the data collected from 30 sample plots of $D$. sissoo laid out in IGNP area of Rajasthan State (India) and measured annually for 5 years. The best approximating model was selected based on the fit statistics among the models tested in the study. The model develop was evaluated based on quantitative and qualitative statistical criteria which showed that the model is statistically sound in prediction. The model can be safely applied on $D$. sissooo plantations in the study area or areas having similar conditions.
\end{abstract}

Key Words: yield, variable density, D. sissoo, arid region, India, fit statistics

\section{Introduction}

Forest yield tables and growth models are an essential source of information to forest management and forest planning. Their predictions have made it possible to develop the idea of a sustainable yield and to optimize silvicultural management. Today, there are numerous yield tables and growth models used all over the world. However, in certain regions and for some species, growth and yield esti- mates are obsolete or even not available. This is only partly due to the fact that there are no basic inventory data sets accessible (Nagel and Kehr 1997).

Yield estimation is an important part of a stand model and is indispensable when silvicultural decisions are based on economic criteria. It is impossible to measure the stand volume directly in the field. Therefore, this quantity must be calculated from other variables, such as basal area and dominant height, and sometimes also stand age. Thus,

Received: May 16, 2012. Revised: June 6, 2012. Accepted: July 26, 2012. 
stand volume is often a derived quantity, a by-product of modelling. Regional yield forecasts are based on aggregate area information, typically in the form of age-class distributions, involving a considerable lumping of area detail with an associated uncertainty. General yield models, covering all possible growing sites and silvicultural regimes, are simply not available (Gadow and Hui 1999).

A yield table is essentially a tool of long term planning. It is a type of growth or 'experience' table which lists expected productivity/volumetric yield for a given age, site or crop quality and sometimes other indices such as density. Thus, yield tables usually refer only to even-aged stands. Data to prepare such tables may be obtained from permanent sample plots, temporary sample plots or stem analysis. Permanent sample plot information is by far the most satisfactory on which to base yield tables (Gadow and Hui 1999).

The main purpose of yield tables is to provide estimates of present yield and future increment and yield. The tables may be presented in tabular or graphical form or in the form of a regression equation relating yield to age, site and stand density. There are three main types of yield table, viz. normal, empirical and variable density (Husch et al. 1982).

Yield tables that represent the normal development of a forest are a frequently used data base for regional timber resource forecasting. A yield table estimates the production potential for a discrete number of site quality classes, assuming average silvicultural treatment. The volume of the remaining stand may be modelled as a function of site class and age (Smaltschinski 1997, p. 132). An empirical yield function can be used for regional resource forecasting (Shvidenko et al. 1995).

A normal yield table is based on two independent variables, age and site (species constant), and applies to fully stocked (or normal) stands. It depicts relationships between volume/unit area together with other stand parameters and the independent variables. 'Normal' is an unfortunate term as fully stocked stands are rather unusual. Since only two independent variables are involved, normal yield tables are conveniently constructed by graphical means. The density variable is held constant by attempting to select sample plots of a certain fixed density assessed as full (or normal) stocking. The data presented in normal yield tables are averages derived from many stands considered to be fully stocked at the time they were sampled. In contrast to normal yield tables, empirical yield tables are based on average rather than fully stocked stands. This simplifies the selection of stands for sampling. The resulting yield tables describe stand characteristics for the average stand density encountered during the collection of field data (http://fennerschool-associated.anu.edu.au).

Normal and empirical yield tables essentially have the same limitations, namely: the difficulty of locating fully stocked stands or representative average stocked stands from which to collect the basic data; stocking may not have always been 'fully stocked' or 'average'; the problem of selecting correction factors to apply to stands of density other than normal or average (http://fennerschool-associated. anu.edu.au).

The methods of yield forecasting are much simpler in fully-stocked unthinned cyclic forests than the methods required for forests with variable degree of stocking. More refined methods of simulation need to be applied where intensive forestry is practiced including a method for considering the effects of different levels of stand density which is often expressed using the variable degree of stocking (Gadow and Hui 1999).

The limitations of normal and empirical yield tables led to the development of techniques for compiling tables with three independent variables, stand density being included as the third variable: hence the term variable density yield tables. Basal area/unit area, mean diameter or stand density indices are used to define the density classes (Davis 1966; Prakash 1986). Such yield tables are particularly useful for abnormal stands e.g. abnormal due to early establishment problems, insect and fungal attack, drought, fire, fluctuating demands for produce, etc (http://fennerschoolassociated. anu.edu.au). It makes up shortcoming of normal yield table and empirical yield table. Single stand growth and yield can be estimated from variable density yield table and hence it is more emphasised by the foresters (Longchang et al. 1991).

Mathematical models for estimating timber yields are usually developed by fitting a suitable equation to observed data. The model is then used to predict yields for conditions resembling those of the original data set. It may be accurate for the specific conditions, but of unproven accuracy or even entirely useless in other circumstances (Gadow and Hui 1999). 
To improve agriculture and living conditions of the people in the drought prone arid parts of Rajasthan State in India, the Indira Gandhi Canal Project (IGNP) was developed. To combat the desertification, the State Forest Department has taken up massive afforestation activities along the main canal and its distributaries by planting various tree species like Acacia nilotica, Dalbergia sissoo, and Eucalyptus camaldulensis. The plantations were raised throughout the area at different sites with varying stand density. Dalbergia sissoo is one of the most useful and important timber tree species grown in various part of India and is valued in the domestic market. There is a high demand for $D$. sissoo timber.

The objective of the present study was to develop variable density yield model for $D$. sissoo that can be used by the forest managers for the productivity/yield estimation and management of plantations of this species in the study area.

\section{Materials and Methods}

\section{Study area}

The IGNP area is characterized by large variation in the diurnal and seasonal temperatures. The maximum daily summer temperature often exceeds $46-48^{\circ} \mathrm{C}$; the night temperature occasionally touches $0^{\circ} \mathrm{C}$ owing to cold waves associated with the western disturbance, which may cause frost conditions. The mean monthly maximum temperature varies between $39.5^{\circ} \mathrm{C}$ and $42.5^{\circ} \mathrm{C}$ while mean monthly minimum temperatures vary between $14-16^{\circ} \mathrm{C}$. Soil temperature in desert sandy tracts often reaches $62^{\circ} \mathrm{C}$ during May and June and they remain higher than the air temperature at least by $10^{\circ} \mathrm{C}$ (Tewari and Kumar 2005). The mean annual rainfall in the area varies from $100 \mathrm{~mm}$ to $400 \mathrm{~mm}$ (http://waterresources.rajasthan.gov.in/1 climate.htm). The major quantity of rainfall is received during the southwest monsoon season (July-September). The number of rainy days varies from 8 to 17 days in the area. The mean monthly relative humidity in the IGNP area fluctuates largely during the year from 15 to $80 \%$. The mean evaporation in the area varies from 2.7 to $4.7 \mathrm{~mm}$ per day in winter and 13.2 to $15.3 \mathrm{~mm}$ in the summer with the annual mean being of the order of 7.3 to $8.5 \mathrm{~mm}$ per day. A strong wind is the characteristic feature of the summer and monsoon season in the area, which often causes soil erosion. Wind speeds as high as $130 \mathrm{~km}$ per hour have been experienced during the summer months. Dust storms are also common in the region (3-17 days per year). Droughts are a recurring feature of the area and often persist for 2-3 years (Tewari and Kumar $2005)$. The terrain of the area is very undulating consisting of moving sand dunes, dry undulating plains of hard sand and gravelly soil and rolling plains of loose sand. The soil is rich in potash but poor in nitrogen and low in organic matter with very low productivity. There is presence of semi-consolidated lime concretionary or gypsum strata in many places. The soils are coarsely textured with a low water retention capacity (http://waterresources.rajasthan.gov.in/1soil.htm).

\section{Plantation establishment}

The most common form of establishment of $D$. sissoo in the study area is through raising the seedlings in polybags in the nursery and planting in the field into pits at the onset of the monsoon as block plantations. During 1970-1980, the planting density was approximately 2,500 stems per hectare at about $2 \times 2 \mathrm{~m}$ spacing. Later the spacing was changed to $2 \times 3 \mathrm{~m}$ and $3 \times 3 \mathrm{~m}$ and even to $3 \times 5 \mathrm{~m}$ and $5 \times 5 \mathrm{~m}$. The rotation length of this species in the study area is fixed as 25 years depending upon site, climate and the type of plantations. Furrow irrigation was applied. Under this system $0.30 \mathrm{~m}$ deep furrows having bottom width of $0.30 \mathrm{~m}$ and top width $0.40 \mathrm{~m}$ were made. Watering schedule was 8 , $10,6,5,3,2$ and 1 in the first eight years. Fertilizers DAP and Urea, were also applied in the doses of $25 \mathrm{gm} /$ plant. The response to fertilizer and irrigation was very good in terms of growth and yield.

\section{Data and field procedure}

Thirty sample plots of $D$. sissoo were laid out at various locations throughout the IGNP area, covering the available age groups, stand densities and sites, using stratified multistage sampling. Each plot was representative of the growing conditions in the stand. The size of the plots was 0.09 ha $(30 \times 30 \mathrm{~m})$ and the plots were permanent in nature. For identification and demarcation, trenches were dug at the four corners of the plot and the trees inside the plot were numbered and enumerated. The check trees (closest trees bordering the sides of the plot) surrounding the plots were marked with rings. The study was started in 1995 and measurements were taken in the sample plots annually for 
Table 1. Summary details of the data in the thirty plots of Dalbergia sissoo

\begin{tabular}{|c|c|c|c|c|c|c|c|c|c|c|c|}
\hline \multirow{2}{*}{$\begin{array}{l}\text { Plot } \\
\text { no. }\end{array}$} & \multirow{2}{*}{$\begin{array}{l}\text { Site index } \\
(\mathrm{m})^{*}\end{array}$} & \multicolumn{2}{|c|}{ Age (years) } & \multicolumn{2}{|c|}{ Density (stems/ha) } & \multicolumn{2}{|c|}{ Volume per ha $\left(\mathrm{m}^{3}\right)$} & \multicolumn{2}{|c|}{ Dominant height $(\mathrm{m})$} & \multicolumn{2}{|c|}{ Basal area $\left(\mathrm{m}^{2} / \mathrm{ha}\right)$} \\
\hline & & Initial & Final & Initial & Final & Initial & Final & Initial & Final & Initial & Final \\
\hline 1 & 12.89 & 7.2 & 11.2 & 1,616 & 1,548 & 42.82 & 73.70 & 11.62 & 11.56 & 13.83 & 16.25 \\
\hline 2 & 17.61 & 7.2 & 11.2 & 1,496 & 1,073 & 64.24 & 73.25 & 13.68 & 15.47 & 18.28 & 15.54 \\
\hline 3 & 14.65 & 8.2 & 12.2 & 2,289 & 1,929 & 49.00 & 65.51 & 11.40 & 13.55 & 12.24 & 13.68 \\
\hline 4 & 10.12 & 3.2 & 7.2 & 1,850 & 1,650 & 11.46 & 32.60 & 9.14 & 9.90 & 4.82 & 8.93 \\
\hline 5 & 14.04 & 11.2 & 14.2 & 2,423 & 2,123 & 125.14 & 156.71 & 12.27 & 13.92 & 22.63 & 27.24 \\
\hline 6 & 17.81 & 10.2 & 11.5 & 2,537 & 2,502 & 93.65 & 111.96 & 14.54 & 15.62 & 19.85 & 21.51 \\
\hline 7 & 14.33 & 17.7 & 19.1 & 832 & 796 & 78.71 & 80.04 & 14.40 & 14.43 & 14.20 & 14.32 \\
\hline 8 & 12.29 & 23.7 & 27.7 & 476 & 476 & 236.99 & 299.50 & 21.26 & 22.78 & 29.16 & 32.80 \\
\hline 9 & 17.17 & 8.3 & 11.3 & 1,902 & 1,891 & 62.72 & 111.14 & 12.34 & 14.96 & 14.76 & 20.29 \\
\hline 10 & 18.68 & 8.3 & 11.3 & 1,644 & 657 & 165.20 & 109.61 & 18.21 & 18.48 & 23.59 & 14.11 \\
\hline 11 & 13.90 & 7.5 & 10.6 & 1,972 & 1,945 & 53.14 & 67.29 & 11.47 & 13.01 & 13.84 & 15.14 \\
\hline 12 & 10.91 & 30.5 & 33.4 & 356 & 342 & 177.70 & 193.37 & 18.52 & 19.35 & 23.22 & 23.96 \\
\hline 13 & 13.05 & 8.5 & 11.6 & 1,567 & 1,361 & 42.23 & 48.60 & 11.24 & 12.24 & 10.79 & 11.00 \\
\hline 14 & 11.86 & 7.5 & 10.6 & 1,924 & 1,347 & 45.21 & 43.91 & 9.35 & 10.64 & 13.09 & 11.10 \\
\hline 15 & 16.63 & 8.5 & 11.6 & 1,592 & 1,111 & 107.33 & 115.23 & 13.60 & 14.94 & 20.79 & 19.74 \\
\hline 16 & 18.32 & 9.5 & 12.6 & 1,356 & 1,149 & 99.90 & 125.63 & 14.72 & 17.10 & 18.50 & 19.56 \\
\hline 17 & 16.98 & 9.5 & 12.6 & 1,651 & 937 & 120.58 & 82.73 & 19.09 & 15.99 & 20.19 & 13.59 \\
\hline 18 & 17.70 & 8.5 & 11.6 & 1,438 & 1,292 & 84.00 & 120.22 & 14.25 & 16.49 & 16.96 & 20.47 \\
\hline 19 & 17.64 & 8.5 & 11.6 & 1,599 & 1,429 & 136.33 & 154.77 & 16.83 & 17.30 & 22.31 & 24.04 \\
\hline 20 & 9.81 & 7.5 & 8.7 & 2,632 & 2,179 & 20.28 & 19.38 & 8.71 & 9.00 & 8.67 & 7.65 \\
\hline 21 & 17.19 & 6.5 & 9.6 & 1,684 & 1,332 & 91.43 & 133.69 & 16.34 & 19.78 & 19.46 & 20.12 \\
\hline 22 & 11.89 & 8.5 & 10.5 & 2,046 & 1,228 & 67.03 & 51.33 & 11.43 & 11.62 & 16.45 & 11.86 \\
\hline 23 & 13.80 & 13.5 & 15.5 & 1,622 & 569 & 95.15 & 45.95 & 13.51 & 13.42 & 18.26 & 8.44 \\
\hline 24 & 8.65 & 29.0 & 31.0 & 608 & 608 & 181.80 & 214.75 & 19.86 & 21.20 & 23.69 & 25.80 \\
\hline 25 & 15.22 & 19.0 & 21.0 & 861 & 694 & 155.63 & 164.17 & 18.39 & 19.72 & 20.27 & 19.99 \\
\hline 26 & 13.42 & 9.3 & 11.3 & 1,538 & 905 & 86.29 & 53.88 & 14.06 & 13.68 & 16.40 & 9.95 \\
\hline 27 & 17.21 & 8.3 & 10.3 & 1,636 & 1,249 & 89.75 & 87.41 & 13.24 & 14.78 & 17.27 & 15.09 \\
\hline 28 & 13.12 & 8.3 & 10.3 & 2,500 & 1,692 & 73.22 & 67.05 & 12.30 & 12.63 & 16.28 & 14.13 \\
\hline 29 & 16.41 & 7.3 & 9.3 & 1,884 & 1,768 & 93.26 & 103.98 & 12.49 & 13.98 & 17.02 & 17.65 \\
\hline 30 & 9.87 & 9.3 & 11.3 & 1,560 & 910 & 31.86 & 23.78 & 9.78 & 9.94 & 10.23 & 8.09 \\
\hline
\end{tabular}

*At base age 15 years.

five years. The study period was from 1995 to 2001 . Trees, representing different diameter classes in the plots, were felled from the surround of the plots for volume estimation. A total of 90 trees were felled from the plantations (30 sample plots). For the computation of total volume, stem and branch wood with a minimum diameter of $5 \mathrm{~cm}$ was considered. The volume was then calculated by dividing the stem and branches into logs of $3 \mathrm{~m}$ length, measuring the mid-diameters and applying Huber's formula to estimate individual log volumes. Equations showing the relationship between volumes and $\mathrm{D}^{2} \mathrm{H}$ were derived for volume prediction. The volume equation developed was applied on the trees within the plots to estimate yield i.e. wood volume per hectare (Tewari and Kumar 2005). The plot data included records of age, quadratic mean diameter, average height, stems per hectare, top diameter, dominant height, basal area per hectare, and timber \& wood volume (over-bark and under-bark) per hectare (Tewari and Kumar 2005). Some of these details are presented in Table 1.

Site index, the dominant height of the trees in a stand at a given reference age, has been the most widely used means for estimating potential forest site productivity (Payandeh and Wang 1994). The dominant height is practically independent from the stand density (Kramer 1988) and thus 
is used as an indicator of the site productivity. For estimating site index, the base-age was selected as 15 years. The site index varied from $8.65 \mathrm{~m}$ to $18.68 \mathrm{~m}$. Accordingly five site classes/qualities were defined at $2 \mathrm{~m}$ intervals. The development of the dominant height, the basal area and the stems per ha over the stand age has been presented in Fig. 1.

The following equation (modified from Nagel and Kehr 1997) was found best among all other equations tested and, hence, was used to develop variable density yield model for D. sissoo plantations in IGNP area of Rajasthan using the data from the 30 sample plots measured annually for five years:

$$
V=e^{a+b * \ln \left(\frac{T H}{A}\right)+c * \ln (N)+d * \ln (B A)}
$$

where, $\mathrm{V}=$ over-bark volume/ha $\left(\mathrm{m}^{3}\right), \mathrm{TH}=$ dominant height of the trees in the stands $(\mathrm{m}), \mathrm{A}=$ age of the stand

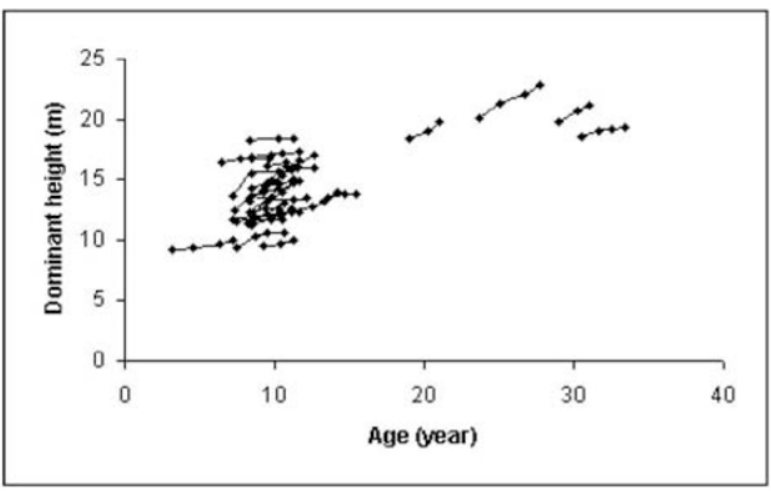

(A) Height growth in the plots with increasing age

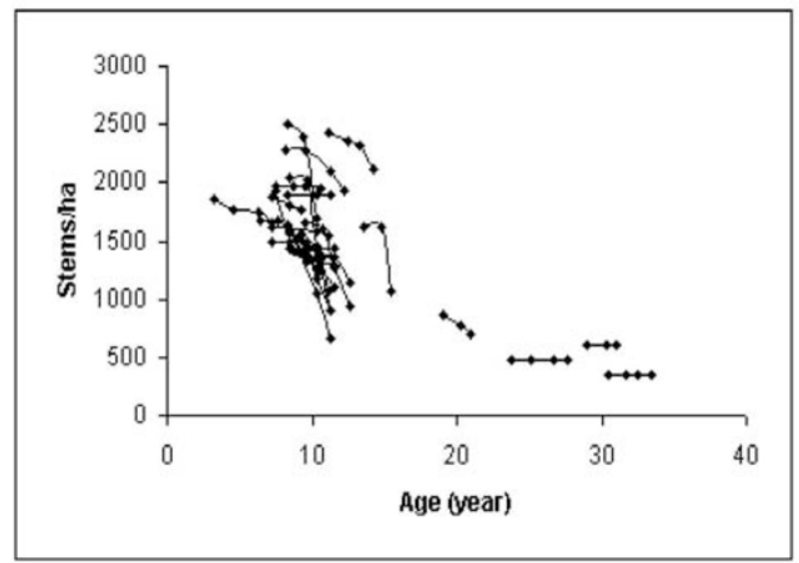

(C) Stems/ha vs. age (years), $\mathrm{N}=$ stems $/$ ha, $\mathrm{BA}=$ basal area $/ \mathrm{ha}\left(\mathrm{m}^{2}\right)$.

\section{Model evaluation}

The qualitative and quantitative evaluation of model is a very important part of growth modelling. Graphical analysis of residuals searching for discrepancies or patterns is an important step in evaluating the fitted model (Gadow and Hui 1999). Residuals should be graphically examined to check for any trend. Average bias $(\bar{E})$, model efficiency $(\mathrm{MEF})$, and the variance ratio (VR) are important indices of model precision. The average bias describes the directional magnitude, i.e. the size of expected under- or overestimates. The model efficiency index is analogous to $\mathrm{R}^{2}$ and provides a relative measure of performance. The variance ratio is the ratio of estimated to observed variance. The expressions for these indices with their ideal values are given below:

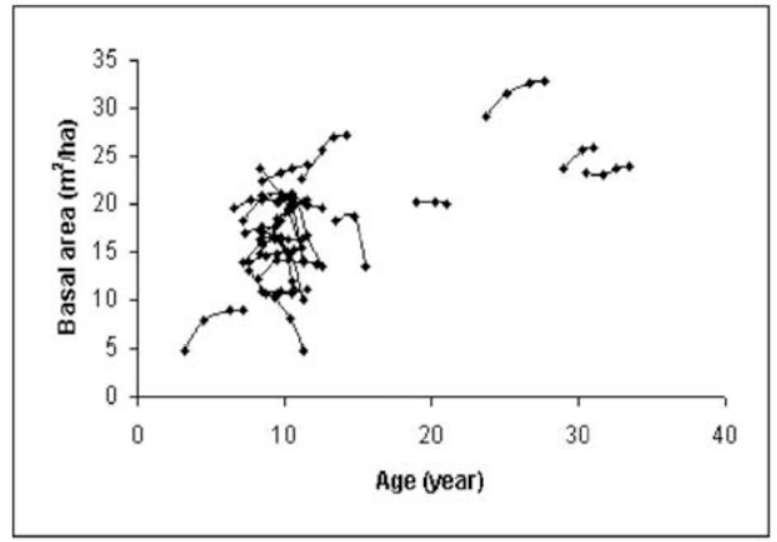

(B) Basal area growth with increasing age

Fig. 1. (A) Height development, (B) basal area development and (C) stem number development with age 


\begin{tabular}{lcc}
\hline \multicolumn{1}{c}{ Criteria } & Formula & Ideal value \\
\hline Bias & $\bar{E}=\sum_{i=1}^{n} \frac{\left(y_{i}-\hat{y}_{i}\right)}{n}$ & 0 \\
Model efficiency & $M E F=\frac{\sum\left(y_{i}-\hat{y}_{i}\right)^{2}}{\sum\left(y_{i}-\bar{y}\right)^{2}}$ & 0 \\
Variance ratio & $V R=\frac{\sum\left(\hat{y}_{i}-\overline{\hat{y}}_{i}\right)^{2}}{\sum\left(y_{i}-\bar{y}\right)^{2}}$ & 1 \\
\hline
\end{tabular}

Relative error in prediction (RE \%) may also be calculated using the formula:

$$
R E \%=\frac{\left.100 \sqrt{\sum_{i=1}^{n}\left(N_{i}-\hat{N}_{i}\right)^{2}} /(n-p)\right)}{\bar{N}}
$$

where $N_{i}, \hat{N}_{i}$ and $\bar{N}_{i}$ are the observed, predicted and average values of the volume/ha, respectively; $n$ is the total number of observations used to fit the models; and $p$ is the number of parameters in the model.

\section{Results and Discussion}

The information given in Table 1 showed that site index varied from 8.65 to $18.68 \mathrm{~m}$, age from 3.2 to 33.4 years, density 342 to 2642 trees/ha, dominant height from 8.71 to $22.78 \mathrm{~m}$, volume/ha from 11.46 to $299.50 \mathrm{~m}^{3}$ and basal area/ha from 4.82 to $27.24 \mathrm{~m}^{2}$.

It is evident from Fig. 1A that the data for most of the plots are concentrated between 6 to 13 years of age. Fig. 1B shows a decrease in basal area of some of the plots due to large mortality of trees in these stands (plot nos. 2, 10, 14, $15,17,22,23,25-28,30$ in Table 1). A considerable decline in stems/ha has been observed in some stands (Fig. 1C) due to heavy mortality as a result of over crowding and anthropogenic factors.
The data collected from the 90 sample trees felled from the surround of sample plots were used for volume estimation. Variable density yield model was developed by fitting Equation 1 to the 5 year's dataset of 30 sample plots taking wood volume (over-bark) per hectare as dependent variable and age, dominant height, number of trees per hectare and basal area per hectare as independent variables. The values of parameter coefficients, coefficient of determination and mean squared error obtained by fitting the equation to the data set are given in Table 2 .

The standard errors show that all the partial regression coefficients were statistically significant. The $R^{2}$ value is generally high while RMSE values are very low. This shows the high accuracy and precision of the equation used in making yield predictions in D. sissoo plantations in the study area under varying age, density and site conditions.

The residuals for model developed were randomly distributed and there were no systematic trends in the errors (Fig. 2), and hence no serious violation of normality assumption. The average bias for the model was -0.084 which is only $0.08 \%$ of the mean value of the volume/ha. Thus the model is almost free from bias. The values for

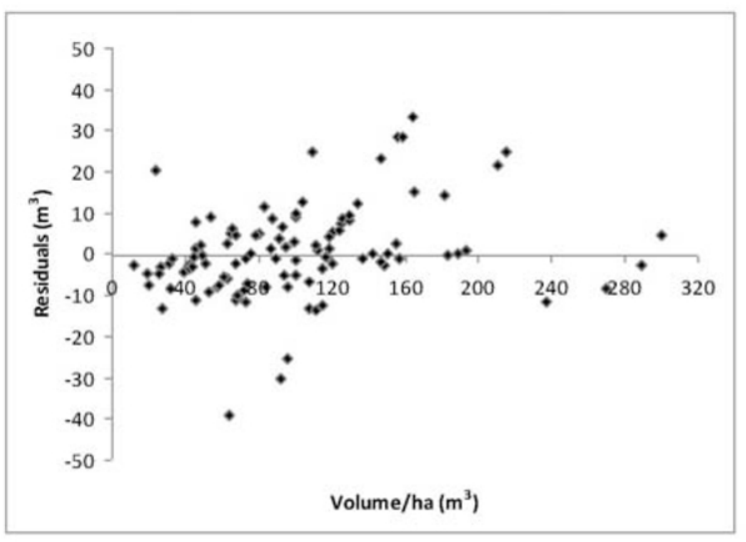

Fig. 2. Plot of residuals over observed values.

Table 2. Parameter coefficients and fit statistics for variable density yield model

\begin{tabular}{lcccccc}
\hline & $\mathrm{a}$ & $\mathrm{b}$ & $\mathrm{c}$ & $\mathrm{d}$ & $\mathrm{R}^{2}$ & $\mathrm{RMSE}\left(\mathrm{m}^{3}\right)$ \\
\hline Value & 2.05930 & 0.12150 & -0.24769 & 1.48353 & 0.949 & 13.06308 \\
Std. error & 0.31013 & 0.04905 & 0.03127 & 0.05240 & & \\
\hline
\end{tabular}

RMSE, Root Mean Square Error. 
MEF and VR were 0.037948 and 0.94418 respectively which is very close to their ideal value of 0 and 1 . This indicated that the model is statistically sound in prediction. The average relative discrepancy between observed and predicted values was only $1.08 \%$.

The model may be applied to any plantations of $D$. sissoo in the study area or areas having similar conditions to that of study area, though with caution. If the model is applied in other areas having different conditions from the study area, the model first should be validated on an independent data set from that area otherwise it may produce fairly inaccurate results.

A regional yield model is a useful tool for evaluating the effects of different harvest levels on a given age-class distribution and a simple age-class simulation is often the only feasible way to predict the dynamic development of a forest resource on a regional basis. The method involves, however, considerable aggregation over growing sites, forest types and management regimes.

Projections based on yield tables need to be adjusted for variable density. This may be done using tables of reduction factors (Kramer and Akça 1987) or specific growth reduction functions for adjusting current increment in accordance with the actual degree of stocking (Smaltschinski 1997 , p. 155).

Variable density yield model too have some limitations (which apply also to normal and empirical tables), namely:

- No confidence limits are attached to trends;

- Extrapolations are made outside and beyond thinning regimes and ages sampled;

- Volume functions used are mostly two-dimensional and of regional application;

- Volumes are computed for normal trees only and no account is taken of malformation and other such factors affecting recoverability;

- Usually, no account is taken of the pruned component of a stand.

\section{Conclusions}

Variable density model has been developed for irrigated plantations of D. sissoo planted in the Indira Gandhi Canal Project area in arid tract of Rajasthan state in India. The model developed was evaluated based on qualitative and quantitative criteria which showed that the model is statistically sound in prediction. Thus the model can be applied well on $D$. sissooo plantations in the study area or areas having similar conditions to that of study area.

\section{References}

Davis KP. 1966. Forest management: Regulation and valuation. 2nd ed. New York, McGraw-Hill, pp 519.

Gadow Kv, Hui GY. 1999. Modelling forest development. Kluwer Academic Publisher, Dordrecht, pp 213.

http://fennerschoolassociated.anu.edu.au/mensuration/Brackand Wood 1998/S_GROWTH.HTM (downloaded on 31.03.2012).

http://waterresources.rajasthan.gov.in/1 climate.htm (downloaded on 15.05.2012).

http://waterresources.rajasthan.gov.in/1soil.htm (downloaded on 15.05.2012).

Husch B, Miller CI, Beers TW. 1982. Forest Mensuration. 3rd ed. John Wiley and Sons, New York, NY, pp 402.

Kramer H. 1988. Waldwachstumslehre. Paul Parey, Hamburg, Berlin, pp 374.

Kramer H, Akça A. 1987. Leitfaden zur Waldmeßlehre. J.D. Saunder's Verlag, Frankfurt a.M., 287 p.

Longchang Lee, Wenkang Hao, Guoqing Weng. 1991. Study on the method of constructing variable-density yield table. Journal of Forestry Research 2: 95-99.

Nagel J, Kehr IC. 1997. Instant Yield Programme (IYP). Paper presented at the XI World Forestry Congress organized at Antalya. Turkey during 13-22.

Payandeh B, Wang Y. 1994. Relative accuracy of a new base-age invariant site index model. Forest Science 40: 341-348.

Prakash R. 1986. Forest management. International book distributors, Dehradun, 1986.

Shvidenko A, Venevsky S, Raille G, Nilsson S. 1995. A system for evaluation of growth and mortality in Russian forests. Water, Air and Soil Pollution 82: 333-348.

Smaltschinski T. 1997 Großregionale Holzaufkommensprognosen und nationale Forstinventuren. Unpublished manuscript, University of Göttingen, Germany, pp 199.

Tewari VP, Kumar VSK. 2005. Growth and yield functions for Dalbergia sissoo plantations in the hot desert of india grown under irrigated conditions. Journal of Tropical Forest Science 17: 87-103. 